\title{
Fotokapan Görüntülerinde Yerel Öznitelikler ile Nesne Tespiti
}

\author{
Object Detection on Camera-Trap Images with Local Features
}

\author{
Emrah ŞIMSŞEK ${ }^{1,2, a}$, Barış ÖZYER*2,b ${ }^{\text {, Gülşah TÜMÜKLÜ ÖZYER }}{ }^{2, c}$ \\ ${ }^{I}$ Recep Tayyip Erdoğan Üniversitesi, Mühendislik Fakültesi, Bilişim Sistemleri Mühendisliği Bölümü, 53020,Rize \\ ${ }^{2}$ Atatürk Üniversitesi, Mühendislik Fakültesi, Bilgisayar Mühendisliği Bölümü,25240, Erzurum
}

• Geliş tarihi / Received: 09.01.2019 • Düzeltilerek geliş tarihi / Received in revised form: $22.05 .2019 \quad$ • Kabul tarihi / Accepted: 19.06 .2019

\begin{abstract}
$\ddot{O} z$
Fotokapanlar doğal ortamda yaşayan canlıların davranışlarını izlemek amacıyla yaygın olarak kullanılan cihazlardır. Fotoğraf ve video kaydı yapan bu cihazlar ile doğal görüntülerde yapılan nesne (hayvan veya insan) tespiti işlemi, arka planının karmaşık yapıda olması, ışık şiddeti yetersizliği, ışık şiddeti değişimi, nesnenin parçalı bulunması gibi nedenlerden dolayı zor bir problemdir. Ayrıca nesnenin hareketli olması, görüntü içerisinde bulunduğu konumun tespit edilmesini zorlaştırmaktadır. Son yıllarda kullanılan yerel öznitelikler konum bilgisi içerdiğinden, hem konumlandırma problemine çözüm olmakta hem de yerel öznitelik dönüşüm yöntemlerinin içerdiği ölçek, dönme, afin dönüşümü, aydınlatma değişimi gibi zorluklara karşı değişmezlikler sayesinde daha başarılı tespit işlemi yapılabilmektedir. Bu çalışmada foto-kapan görüntülerinde yerel öznitelik dönüşüm yöntemleri olan Ölçek Değişmez Öznitelik Dönüşümü (Scale Invariant Feature Transform-SIFT), Hızlandırılmış Sağlam Öznitelikler (Speeded Up Robust Features-SURF), İkili Sağlam Bağımsız Temel Öznitelikler (Binary Robust Independent Elementary Features-BRIEF), Yönlendirilmiş Hızlı ve Sağlam Brief Öznitelikleri (Oriented Fast And Robust Brief-ORB), öznitelik eşleştirme yöntemlerinde kullanılarak nesne tespiti gerçekleştirilmiştir. Hatalı yerel öznitelik eşleşmelerinin elenmesi için yüzdelik ve medyan tabanlı aykırılık tespiti ile k-en yakın komşu öznitelik eleme yöntemleri kullanılmıştır. Çalış̧mada öznitelik dönüşüm yöntemleri ile elde edilen nesne tespit başarıları, eşleşen öznitelik sayıları, sınırlayıcı kutu büyüklükleri, elenen öznitelik sayıları ve bunların nesne tespit başarısına olan etkileri incelenmiştir.
\end{abstract}

Anahtar kelimeler: Fotokapan, Nesne Tespiti, ORB, SIFT, SURF, BRIEF, Yerel Öznitelikler

\begin{abstract}
Camera-traps are the devices that commonly used to monitor the behavior of living creatures in the natural environment. Object (animal or human) detection in the natural image or video by recorded these devices has difficulties such as cluttered background, inefficient light intensity, light intensity change or partial object presence. Furthermore, the fact that the object is moving makes it difficult to determine the position in the image. Since the local features used in recent years contain location information, it is a solution to the problem of localization as well as more successful detection can be made by the invariance of the scale, rotation, affine transformation, lighting change included in the local feature transformation methods. In this study, local feature description methods are used in camera-trap images, such as Scale Invariant Feature Transform (SIFT), Speeded-Up Robust Features-SURF, Binary Robust Independent Elementary Features (BRIEF), Oriented Fast and Robust Brief-ORB was performed with feature matching methods. Percentile and median based outlier detection methods and $k$ nearest neighboring feature elimination methods were used to eliminate incorrect feature matches. In this study, the effect of feature description methods on object detection accuracies, number of matching features, bounding box sizes, number of eliminated features and their effects on object detection success were analyzed.
\end{abstract}

Keywords: Camera Trap, Object Detection, ORB, SIFT, SURF, BRIEF, Local Features

\footnotetext{
${ }^{* 6}$ Barış Özyer; baris.ozyer@atauni.edu.tr; Tel: 044223160 51; https://orcid.org/0000-0003-0117-6983

${ }^{a}$ https://orcid.org/0000-0002-1652-9553 ${ }^{\mathrm{c}}$ https://orcid.org/0000-0002-0596-0065
} 


\section{Giriş}

Foto-kapanlar doğal ortamdaki canlı yaşamı hakkında bilgi toplanmasını sağlayan görüntü ve video kaydı yapan cihazlardır (Kays vd., 2010). Foto-kapan görüntüleri üzerinde bölgede canlıların tespit edilmesi, türlerinin ve nüfuslarının belirlenmesi gibi çalışmalar yapılmaktadır. $\mathrm{Bu}$ çalışmalarda, görüntülerde bulunan canlıların otomatik olarak tespit edilebilmesi için bilgisayarlı görme ve örüntü tanıma yöntemleri kullanılmaktadır. Bu yöntemler kullanılarak görüntüdeki hayvanlar ve insanlar otomatik olarak tespit edilmeye veya tanınmaya çalışılmaktadır. Foto-kapan görüntülerinde yapılan çalışmalarda, nesne tespit etme ve tanıma işlemlerinin yapılmasını zorlaştıran karmaşık ve hareketli arka plan, 1şık yoğunluğu değişimi ve cismin kısmi görünümü gibi önemli problemler bulunmaktadır (Yu vd., 2013; Nguyen vd., 2017; Norouzzadeh vd., 2018; Meek vd., 2014; Andavarapu ve Vatsavayi, 2017). Foto-kapan görüntüleri üzerinde yapılan çalışmalarda, nesne tespit etme ve nesne tanıma olmak üzere iki temel konu hedeflenmektedir. Görüntüde nesne tespiti işlemi, nesnenin görüntüde bulunması ve eğer var ise görüntüdeki konumunun belirlenmesi olarak ifade edilebilmektedir (Chen vd., 2015). Nesne tanıma ise tespit edilen nesnelerin tür veya farklı şekilde sinıflandırılması anlamına gelmektedir. Nesne tespiti amacıyla yapılan çalışmalarda genellikle nesnelere ait model görüntülerin öznitelikleri, foto-kapan görüntülerinde kayan pencere tabanlı yöntemle aranarak nesne tespit işlemi gerçekleştirilmektedir (Yu vd., 2013; Andavarapu ve Vatsavayi, 2017).

Nesne tespit etme ve konumlandırma için bir pencereyi görüntü üzerinde çoklu ölçekler şeklinde kaydırmak en yaygın yaklaşımdır. Bu yerel penceredeki görüntüler aranan nesne veya arka plan şeklinde sınıflandırılarak tespit işlemi gerçekleştirilebilmektedir. $\mathrm{Bu}$ yaklaşım, görüntülerde yüz, yaya ve araba gibi nesneleri tespit etmek için başarıyla kullanılmaktadır (Murphy vd., 2006). Bunun dışında son yıllarda kullanılan bir yaklaşım da, görüntüden yerel özniteliklerini çıkarmak ve sonra tüm olası alt pencerelere bakmak yerine bu noktaların etrafindaki bölgelerin her birini sınıflandırmaktır (Murphy vd., 2006). Görüntüdeki nesnelerin tespit edilmesi ve nesnelerin tanınması, özellikle sınıf içi çeşitlilik, karmaşıklık, tıkanıklık ve poz değişikliklerinin olmasından dolayı bilgisayarlı görüdeki en zorlu problemlerden biridir (Zhang vd., 2007). Görüntüde nesne tespit etme veya nesne tanıma amaciyla kullanılabilecek temelde iki tip öznitelik çıkarılmaktadır. Bunlar global ve yerel özniteliklerdir. Global öznitelikler görüntüyü bir bütün olarak tanımlamakta ve tüm bir nesneyi tek bir vektörle genelleştirmektedir. Yerel öznitelikler ise, görüntüde belirlenen birden çok anahtar nokta ve bu anahtar noktaların tanımlayıcılara dönüştürülmesi ile elde edilmektedir. $\mathrm{Bu}$ tanımlayıcılara dönüştürme işlemi, özniteliğe tıkanma ve karmaşıklığa karş1 dayanıklılık sağlamaktadır. Ancak, her nesne veya görüntü için değişken sayıda öznitelik vektörünün bulunduğu durumları ele almak için özel sinıflandırma algoritmaları gerekebilmektedir (Lisin vd., 2005). Görüntüdeki nesnelerin tespit edilmesi veya tanınması için kullanılabilecek bir yerel öznitelik, yakın komşuluklarından farklılık ifade eden bir görüntü deseni olarak tanımlanmaktadır. Yerel öznitelikler noktalar, kenarlar veya küçük görüntü yamalarıdır. Tipik olarak, bazı ölçümler yerel bir öznitelik üzerinde bulunan bir bölgeden alınmakta ve daha sonra çeşitli uygulamalar için kullanılabilecek tanımlayıcılara dönüştürülmektedir. $\mathrm{Bu}$ yerel öznitelik tanımlayıcıları, parçalara ayırma gereği duymadan nesneleri veya sahneleri tanımaya yarayan sağlam bir görüntü temsili olarak kullanılabildikleri için sıklıkla tercih edilebilmektedir (Tuytelaars ve Mikolajczyk, 2008).

Gerçek görüntülerde nesne tespit etme ve nesne tanıma, görüntüdeki karmaşıklık veya kısmi tıkanıklıktan etkilenmeyen yerel görüntü öznitelikleri kullanmayı gerektirmektedir. Yerel özniteliğin, tekrarlanabilirlik, ayırt edilebilirlik, yerellik, yeterli miktar, doğruluk ve verimlilik gibi özelliklere sahip olması gerekmektedir (Tuytelaars ve Mikolajczyk, 2008). Bu öznitelikler, aydınlatma değişikliğine, 3B dönüşümlere ve ortak nesne varyasyonlarına karş1 değişmezlik sahibi olmalıdır. Öte yandan, öznitelikler farklı nesneleri tanımlayabilmeleri için ayırt edici olmalıdır (Lowe, 1999). Yerel değişmez öznitelikler, yalnızca görüntüleme koşullarındaki değişimlere, oklüzyon veya görüntü dağınıklığına rağmen görüntüdeki benzerliklerin bulunmasını sağlamakla kalmamakta, aynı zamanda görüntü içeriği ile ilgili tanımlama yapabilmektedir (Tuytelaars ve Mikolajczyk, 2008).

Foto-kapan görüntülerinde yapılan nesne tespit etme ve tanıma çalışmalarında farklı yerel ve global öznitelikler kullanılmıştır. Bu çalışmalarda, nesnelerin tespit edilme ve kırpılma işleminin insanlar tarafindan elle yapılmış görüntülerin yerel veya genel öznitelikleri, sinıflandırma yöntemleri ile birlikte kullanılabildiği gibi (Yu 
vd., 2013; Nguyen vd., 2017; Andavarapu ve Vatsavayi, 2017), bu öznitelikler kayan pencere veya sinir ağları tabanlı yöntemlerde kullanılarak nesne tespiti yapılabilmektedir (Nguyen vd., 2017; Norouzzadeh vd., 2018; Zhang vd., 2016; Khorrami vd., 2012). Yapılan çalışmalar incelendiğinde, nesne görüntülerinin insanlar tarafindan tespit edildiği ve arka plandan el ile kırpıldığı çalışmada (Yu vd., 2013), nesneler SIFT ve cLBP (cell-structured Local Binary Pattern) öznitelikleri kullanılarak çok sınıflı SVM (Support Vektor Machine) ile sınıflandırılmıştır. Tespit işleminin otomatik olarak kayan pencere tabanlı yöntemle yapıldığı (Andavarapu ve Vatsavayi, 2017) diğer bir çalışmada ise 5 farklı vahşi hayvan türünün bulunduğu 5000 görüntüde vahşi hayvanların tespit edilmesi ve tanınması amaciyla W-CoHOG (Weighted Co-occurrence Histogram Of Gradients) öznitelikleri ve çok sınıflı doğrusal SVM sınıflandırıcı kullanılmıştır. Sinir ağları kullanılan bir çalışmada ise (Nguyen vd., 2017) piksel yoğunluklarının 0-1 arasına normalize edildiği, $224 \times 224$ piksel boyutlarına dönüştürülmüş eğitim verisi ile eğitilen derin öğrenme tabanlı sinir ağları kullanılmıştır. 1.2 milyon görüntünün eğitim için kullanıldığ1 bir diğer sinir ağları tabanlı çalışmada ise (Norouzzadeh vd., 2018), derin öğrenme ile nesneler üzerinde tanıma, sayma, davranış belirleme gibi işlemler gerçekleştirilmiştir ve bu çalışmada 3 gizli katman kullanılmış olup, bu katmanlarda sırasıyla kenarlar, köşeler ve motifler, nesne parçaları işlenmiştir. Çapraz doğrulama kullanılan (Zhang vd., 2016) bir çalışmada ise, görüntüdeki 20x20 piksel büyüklügündeki parçaların arka plan olup olmadığının tespit edilmesi amaciyla derin öğrenme tabanlı sinir ağı ve adaptif pencere büyüklügünde kayan pencere tabanlı HOG öznitelikleri ve Fisher vektör kodlaması kullanılmıştır. Çok sayıda hayvan türünün tespit edildiği (Khorrami vd., 2012) çalışmada, görüntüler üzerinde öncelikle Sağlam Temel Bileşen Analizi (RPCA-Robust Principal Component Analysis) ile arka plan analizi yapılmış ve daha sonra yerel entropi ve bağlı bileşen analizi ile nesneler tespit edilmiştir. $\mathrm{Bu}$ çalışmada geniş yer değiştirme optik akış yöntemi ile nesne içeren bölgeler tespit edilmiştir. Sonraki görüntülerde ise nesnenin takip edilmesi ve hareketi ile ilgili bilgi elde edilmesi amaciyla optik akış yöntemi ile görüntüler arasındaki büyük değişikliklerden yararlanılmıştır.

Literatürde yerel öznitelikler ile yapılan çalışmalarda, genellikle yerel öznitelik dönüşümleri birebir eşleştirilmek yerine, bunların istatistiki bilgilerini içeren görsel kelime çantası yaklaşımları tercih edilmektedir. Böyle uygulamalarda görüntüdeki öznitelikler görsel kelime çantası yöntemi ile gruplandırılıp, k-en yakın komşu, destek vektör makineleri ve rastgele orman gibi sınıflandırıcılarda kullanılarak, kayan pencere tabanlı yöntemle, her pencerede ilgili nesnenin olup olmadığına bakılarak tespit işlemi gerçekleştirilmektedir. Bizim bu çalışmamızda, kırpılmış ve arka plandan ayrılmış nesne görüntülerinin SIFT, SURF, BRIEF ve ORB yerel öznitelik dönüşümleri, kaba kuvvet (brute-force) ve k-en yakın komşu öznitelik eşleştirme yöntemlerinde kullanılarak foto-kapan görüntülerinde otomatik nesne tespit işlemi gerçekleştirilmiştir. Hatalı öznitelik eşleşmelerinin elenmesi amacıyla yüzdelik ve medyan tabanlı aykırılık tespiti ve ken yakın komşu öznitelik eleme işlemi uygulanmıştır. Çalışmada öznitelik dönüşüm yöntemleri ile elde edilen nesne tespit başarıları, eşleşen öznitelik sayıları, sınırlayıcı kutu büyüklükleri, elenen öznitelik sayıları ve bunların nesne tespit başarısına olan etkileri incelenmiştir.

Çalışmanın 2. bölümünde kullanılan veri seti, yerel öznitelik dönüşüm yöntemleri, öznitelik eşleştirme yöntemleri ve öznitelik eleme işlemleri anlatılmış olup, 3. bölümde çalışmadan elde edilmiş bulgular ifade edilmiş ve yorumlanmıştır, 4. bölümde ise sonuçlar tartışılmış ve sonraki aşamalarda yapılması planlanan çalışmalar ifade edilmiştir.

\section{Materyal ve Metot}

Fotokapan görüntülerinde yerel öznitelikler kullanılarak nesne tespit için kullandığımız dört aşamadan oluşan sistem modeli Şekil 1'de gösterilmiştir. Öncelikle Şekil 2'de örnek görüntüleri gösterilen veri setinde tespit edilecek nesnelere ait model görüntüler, Şekil 3'te görüldüğü üzere kırpılarak ve arka plandan ayrılarak elde edilmiştir. Birinci aşamada veri setindeki görüntülerin SIFT, SURF, BRIEF ve ORB yöntemleri ile öznitelikleri çıkarılmaktadır. İkinci aşamada görüntülerden elde edilmiş yerel öznitelikler kaba kuvvet (brute-force) ve k-en yakın komşu tabanlı yöntem ile eşleştirilmektedir. Üçüncü aşamada yüzdelik veya ortalama tabanlı aykırılık tespiti ile k-en yakın komşu öznitelik eleme yöntemleri kullanılarak hatalı eşleşmelerin giderilmesi ve elenmesi sağlanmaktadır. Dördüncü aşamada eleme işlemi sonucunda kalan özniteliklerin konum bilgileri kullanılarak tespit edilen nesneye ait sinırlayıcı kutular belirlenmektedir. 


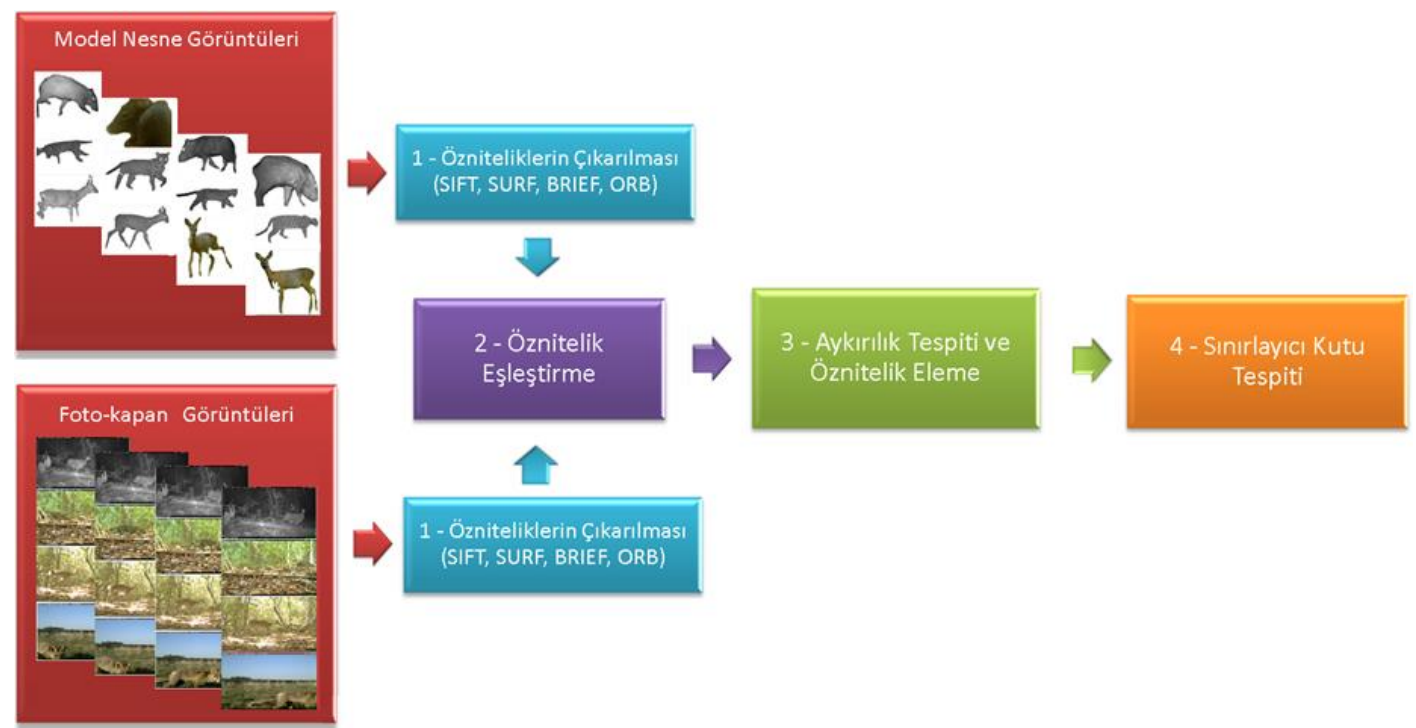

Şekil 1: Sistem modeli

\subsection{Veri Seti}

Çalışmamızda Kays ve arkadaşlarının 2010 yılında yaptığı çalışmada (Kays vd., 2010) elde edilen veri seti kullanılmıştır. Veri setinde 20 farklı hayvan türüne ait 2048x1536 piksel boyutlarında toplam 1016 görüntü bulunmaktadır. Şekil 2'de veri setinden rasgele seçilmiş gece ve gündüz kaydedilmiş görüntüler gösterilmektedir. Gece görüntüleri kızıl ötesi flaş kullanılarak kaydedilmiştir. Veri setindeki görüntülerde nesneler farkl1 ortam, uzaklık ve açılardan elde edilmiş olup tam veya parçalı olabilmektedir. Nesne tespit işleminde her tetikleme için 1 model olmak üzere 20 farklı türe ait 79 model nesne görüntüsü kullanılmıştır.

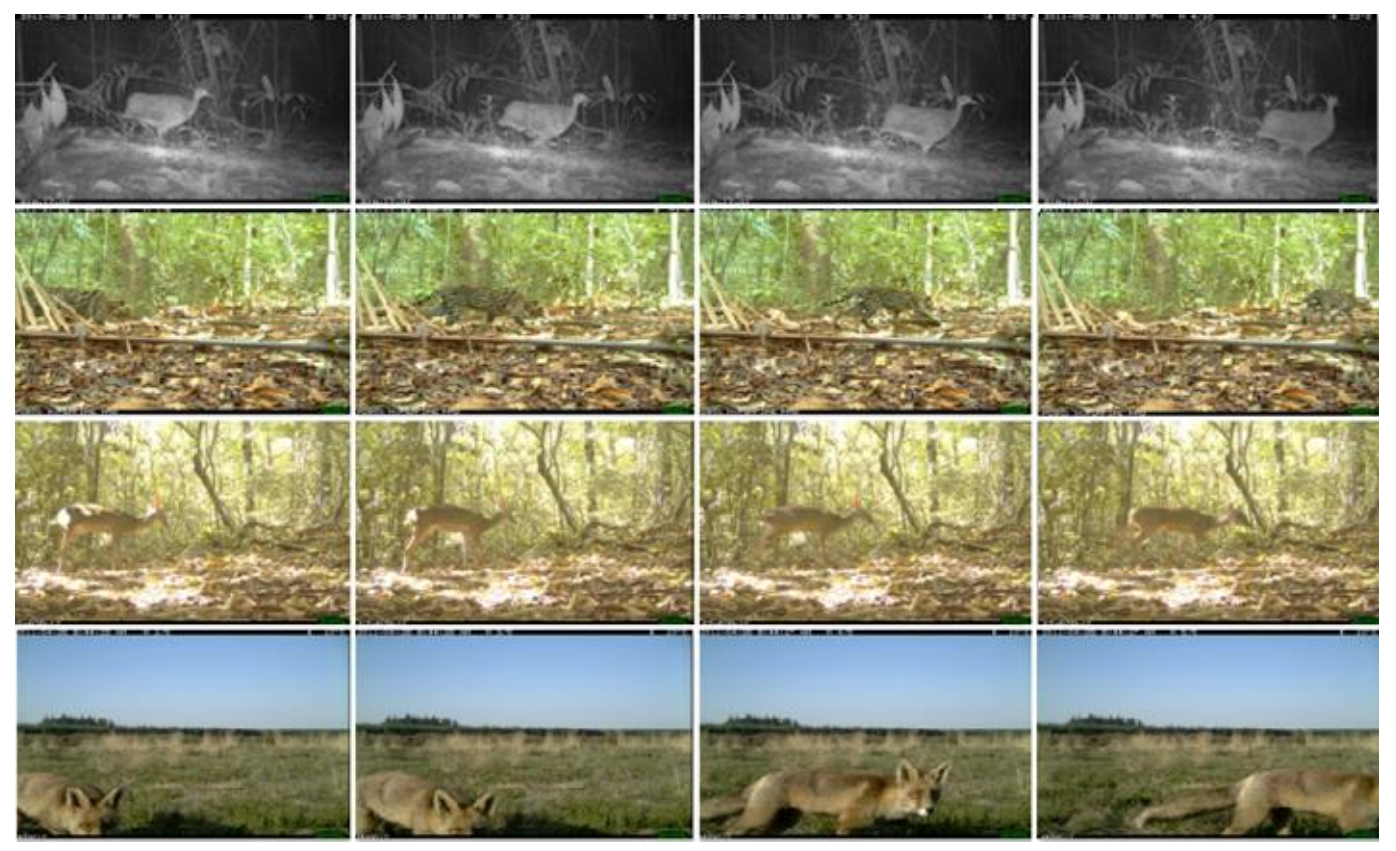

Şekil 2: Veri setine ait örnek görüntüler 


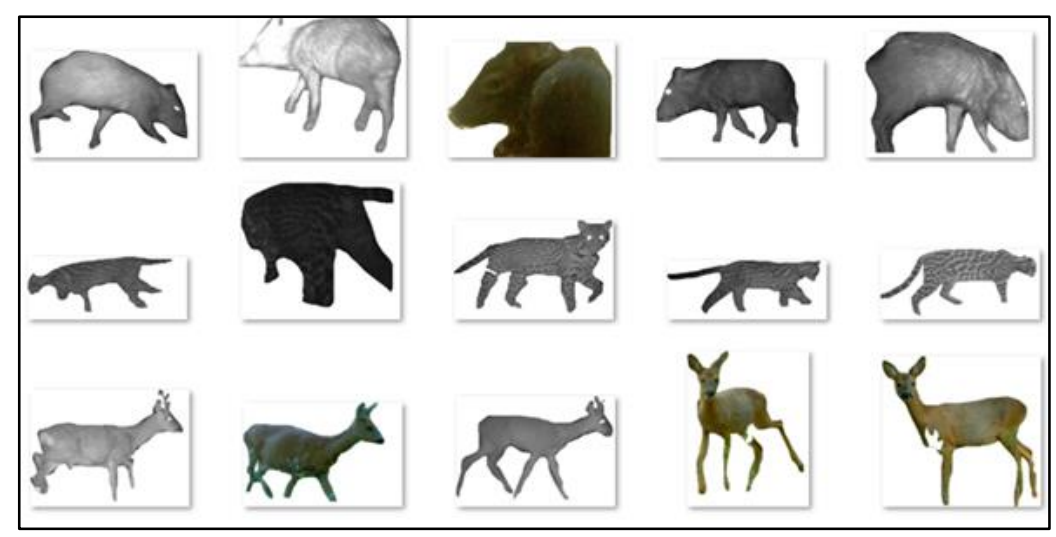

Şekil 3: Nesnelere ait kırpılmış ve arka plandan ayrılmış örnek görüntüler

\subsection{Yerel Öznitelik Çıkarma}

Öznitelik tespiti, görüntü bilgisinin anlamlandırılmasi ve bu noktada belirtilen tipte bir görüntü özelliğinin olup olmadığını görmek için her bir görüntü noktası için yerel bir karar verme işlemidir. Yerel öznitelikler renk, doku, şekil gibi düşük seviyeli özniteliklerden farklı olarak görüntüdeki dönme, ölçek, aydınlatma, gürültü ve afin dönüşümü için dayanıklı olmalıdır (Karami vd., 2017). Bir dizi yerel öznitelik, nesneleri ve sahneleri tanıyabilmek için bölütleme işlemine ihtiyaç duyulmadan sağlam bir görüntü temsili olarak kullanılabilmektedir (Tuytelaars ve Mikolajczyk, 2008). Çalışmamızda bu yerel öznitelik dönüşüm yöntemlerinden SIFT, SURF, BRIEF ve ORB kullanılmıştır.

\subsubsection{SIFT (Scale Invariant Feature Transform)}

Ölçek Değişmez Öznitelik Dönüşümü (SIFT), 1999 y1lında Lowe tarafından geliştirilen bir öznitelik detektörüdür (Lowe, 1999). SIFT detektörü ve tanımlayıcısı nesne tanıma (Lowe, 1999), görüntü birleștirme (Snavely vd., 2008), görsel haritalama (Se vd., 2002), vb. görsel özellikleri kullanan bir dizi uygulamada oldukça başarılı olduğu kanıtlanmıştır (Rublee vd., 2011). SIFT'in nesne tanıma uygulamalarında çok etkili olduğu kanıtlanmış olsa da, büyük bir hesaplama yükü gerektirmesi gibi özellikle gerçek zamanlı uygulamalar için dezavantaja sahiptir (Karami vd., 2017; Lowe, 1999; Rublee vd., 2011; Karami vd., 2017).

Her SIFT özniteliği, görüntü dönüştürme, ölçekleme ve rotasyona göre değişmeyen ve aydınlatma ve yerel görüntü deformasyonlarındaki değişikliklere kısmen değişmeyen bir şekilde yerel görüntü ölçümlerinin bir vektörünü temsil etmektedir (Lowe, 2001). SIFT algoritmasinin 4 temel adımı vardır: 1) tepe noktası seçimi, 2) anahtar nokta yerelleştirmesi ve elenmesi, 3) yönlendirme ataması ve 4) anahtar noktaların tanımlanmasıdır. Birinci aşamada, Gaussian'ın Farkı (DoG) kullanılarak bir ölçek uzayı hesaplanmaktır. $\mathrm{Bu}$ aşamada, Gausssian'ların farkının maksimum veya minimumu olan yerleri arayarak ölçek alanındaki anahtar konumları tanımlanmaktadır. İkinci aşama, anahtar noktaların (keypoint) yerelleştirildiği ve adayların düşük karşıtlığa sahip noktalarının, iyi betimleyici özellikleri olmadığı için elendiği işlemdir. Üçüncü aşama, yerel görüntü eğimi temeline dayanan anahtar noktalara bir yönelim değeri atanmasıdır. Yönelim histogramlarına ait en yüksek bir veya birkaç tepecik öznitelik noktası için yönelim vektörü olarak atanmaktadır. Bu aşamada gradyan yönelimlerinin histogramı kullanılarak dönmeye karşı değişmezlik kazandırılmaktadır. Son aşama ise, görüntü eğim büyüklüğü ve yön belirlenmesine dayanan her bir anahtar noktas1 için yerel görüntü tanımlayıcısının hesaplanmasıdır. Her bir öznitelik noktası için, etrafindaki $4 \times 4$ 'lük bölgede 8 bölmeli bir histogram elde edilerek $128(4 \times 4 \times 8)$ boyutlu bir tanımlayıcı belirlenmektedir. $\mathrm{Bu} 128$ boyutlu vektör, birim uzunluğa dönüştürülerek aydınlatma değişimine karşı kısmen dayanıklılık elde edilmektedir. Ayrıca SIFT öznitelikleri, görüntü gradyanı konumlarını bulanıklaştırarak, afin veya 3D görünüm gibi yerel çeşitliliklere kısmi değişmezlik sağlamaktadır (Lowe, 1999).

\subsubsection{SURF (Speeded Up Robust Features)}

SURF, Hessian matrisine dayanan bir ölçekdeğişmez öznitelik detektörüdür. SIFT'in hızlandırılmış bir yaklaşımı olan SURF tekniği, tespit edilen noktaların kalitesini düşürmeden SIFT'den daha hızlı çalışmaktadır (Bay vd., 2006; 
Karakuş ve Karabörk, 2014). Konum ve ölçeği seçmek için farklı bir ölçü kullanmak yerine, her ikisi için de Hessian detektörü kullanılmaktadır. Hessian matrisi sayısal bir alanın ikinci dereceden kısmi türevlerinden oluşan kare matristir ve kabaca bir dizi kutu tipi filtrenin kullanılmasına benzemektedir (Tuytelaars ve Mikolajczyk, 2008). LoG (Laplacian of Gaussian) kullanılarak, ikinci dereceden türevi alınan görüntüde, ölçek uzayında değişmeyen anahtar noktalar elde edilmektedir. SURF'te SIFT'ten farklı olarak, çok işlem gerektiren ikinci dereceden Gauss türevleri yerine, bir kutu filtre kullanılmaktadır ve bu kutu filtredeki hesaplama işlemi, bütünleşik görüntü kullanılarak kolayca yapılabilmektedir (Tuytelaars ve Mikolajczyk, 2008). Öznitelik tanımlayıcısı, ilgi noktasını tanımlamak için 20x20 piksellik komşu bölgelerin yatay ve dikey yönde Haar dalgacık tepkilerinin dağılımı kullanılmaktadır. Baskın yönelim, 60 derecelik bir kaydırma penceresindeki tüm tepkilerin toplamı hesaplanarak tahmin etmektir. Dalgacık tepkisi, herhangi bir ölçekte çok kolay bir şekilde bütünleşik görüntüler kullanılarak bulunabilmektedir. Bütünleşik görüntü, görüntüdeki piksel değerlerinin dikdörtgen ızgaralar şeklinde hızlı ve etkili olarak toplanabilmesi için kullanılan veri yapısıdır. Ayrıca SURF yönteminde, Laplacian'ın işaretine dayanan eşleşme hızını azaltan ve sağlamlığı arttıran bir indeksleme yöntemi kullanılmaktadır (Bay vd., 2006). Bu indekslemede, temel ilgi noktası için Laplacian (Hessian Matrix) izi kullanılmaktadır. $\mathrm{Bu}$ değerler algılama sırasında zaten hesaplandığından ek hesaplama maliyeti getirmemektedir. Laplacian'ın işareti, koyu arka plandaki parlak lekeleri ters durumlardan ayırmaktadır. Eşleştirme aşamasında, ilgi noktasının yalnızca aynı türde kontrast özellikleri varsa özellikleri karşılaştııılmaktadır. $\mathrm{Bu}$ minimum bilgi, tanımlayıcının performansını düşürmeden daha hızlı eşleştirilmesine olanak tanımaktadır. SURF, bulanıklaştırma ve döndürmeye karşı dayanıklı olmasına rağmen, bakış açısı değişikliği ve aydınlatma değişimine karşı dayanıkl1lık içermemektedir (Bay vd., 2006).

\subsubsection{BRIEF (Binary Robust Independent Elementary Features)}

$\begin{array}{lcr}\text { BRIEF (İkili Sağlam Bağımsız Temel } & \text { Tem } \\ \text { Öznitelikler), öznitelik } & \text { detektörleriyle } \\ \text { birleștirilebilen } & \text { genel amaçlı bir öznitelik } \\ \text { tanımlayıcısıdır. Tipik fotometrik ve geometrik } \\ \text { görüntü dönüşümlerine karşı dayanılıdır. BRIEF, } \\ \text { SIFT için neredeyse benzer eşleştirme } \\ \text { performansına sahip SIFT'den daha az }\end{array}$

karmaşıklık gerektiren başka bir alternatiftir (Calonder vd., 2010). BRIEF yönteminde, yumuşatılmış görüntü yamalarındaki pikseller arasında basit ikili testleri kullanılmaktadır. Performans1, aydınlatma değişimine karş1 dayanıklılık, bulanıklık ve perspektif bozulma gibi birçok açıdan SIFT'e benzemektedir. Bununla birlikte, düzlem içi rotasyona karşı dayanıksızdır (Rublee vd., 2011; Calonder vd., 2010). BRIEF içerisinde bir öznitelik veya anahtar nokta detektörü içermemektedir, yalnızca tespit edilmiş öznitelik veya anahtar noktaların tanımlanması için kullanılmaktadır. Çalışmamızda BRIEF öznitelik tanımlayıcısı, yıldız öznitelik detektörü (star feature dedector) ile birlikte kullanılmıştır.

\subsubsection{ORB (Oriented and Rotated BRIEF)}

ORB (Yönlendirilmiş FAST ve Döndürülmüş BRIEF), FAST (Features from Accelerated Segment Test) anahtar noktası dedektörünün ve BRIEF tanımlayıcısının birtakım modifikasyonları ile birleşmesidir

(Karami vd., 2017; Rublee vd., 2011; Bay vd., 2006). Her iki teknik de iyi performansları ve düşük işlem maliyeti nedeniyle caziptir (Rublee vd., 2011). FAST, gerçek zamanlı uygulamalarda kullanılabilen, diğer köşe detektöründen hızlı olan, gürültüye dayanıklı bir detektördür (Karami vd., 2017). SIFT ve SURF anahtar nokta detektörleri bir yönelim operatörü içermesine rağmen, FAST'de bu işlem bulunmamaktadır (Rublee vd., 2011). FAST algoritması yalnızca köşelerin tespit edileceği dairenin yarıçap1 bilgisini parametre olarak almakta ve ORB yönteminde FAST ile birlikte tespit edilen köşelerin ölçülendirilebilmesi için Harris Köşe Ölçüsü, köşe yöneliminin belirlenmesi için ise yoğunluk ağırlık merkezi (intensity centroid) yöntemi kullanılmaktadır. Yoğunluk ağırlık merkezi yönteminde standart sabitler kullanılarak köşe yönelimleri tespit edilmektedir. Tespit edilen anahtar noktalar, BRIEF kullanilarak tanımlanmaktadır (Rublee vd., 2011).

\subsection{Yerel Öznitelik Çıkarma}

Foto-kapan görüntülerinde nesnelerin tespit edilmesi için kullanılan öznitelik eşleştirme algoritmas1 Algoritma 1'de gösterilmiştir. $\mathrm{Bu}$ algoritmada model nesne görüntülerine ait çıkarılmış yerel öznitelikler, foto-kapan görüntülerindeki öznitelikler ile eşleştirilmektedir. Eşleştirilme işleminde, görüntülerdeki bütün yerel öznitelikler arasında Mahalanobis, Manhattan (denklem 1), Öklid (denklem 2) veya Hamming (denklem 3) uzaklığının hesaplanması ile elde 
edilen mesafe değerleri kullanılmaktadır. Elde edilen bu mesafe değerleri karşılaştırılarak en uygun eşleştirmeye karar verilmektedir.

$d\left(f_{a}, f_{b}\right)=\sum\left|f_{a}-f_{b}\right|$

$d\left(f_{a}, f_{b}\right)=\sum\left(f_{a}-f_{b}\right)^{2}$

$d\left(f_{a}, f_{b}\right)=\sum \operatorname{XOR}\left(f_{a}, f_{b}\right)$

Kaba Kuvvet eşleştirme işleminde (Brute Force Matcher), ilk görüntüdeki bir öznitelik tanımlayıcısının, ikinci görüntüdeki tüm özniteliklerle olan mesafesi denklem (1), denklem (2) ve denklem (3)'e göre hesaplanmış ve en yakın olan eşleşme tespit edilmiştir. Bu eşleştirici iki opsiyonel parametre gerektirmektedir. Birincisi, kullanılacak mesafe ölçümünü belirleyen Manhattan, Öklid ve Hamming değerleridir. Varsayılan olarak uygulanan Öklid, SIFT ve SURF yöntemleri için kullanılmıştır. ORB, BRIEF gibi ikili tabanlı tanımlayıcılar için Hamming mesafesi tercih edilmiştir. İkinci parametre ise, varsayılan olarak kapalı olan çapraz kontrol değişkenidir. $\mathrm{Bu}$ özellik kullanılarak, birinci görüntüdeki özniteliklerin, ikinci görüntüdeki en yakın öznitelik ile eşleştirdiği gibi, ikinci görüntüdeki özniteliklerin birinci görüntüdeki en yakın eşleştirme olup olmadığını da kontrol edilmiştir. k-en yakın komşu eşleştiricisinde ise bir tanımlayıcıya karşılık girilen parametre kadar en yakın komşuluğa sahip 2 tanımlayıcı geriye döndürülmektedir. $\mathrm{Bu}$ iki tanımlayıcı arasındaki mesafe değeri öznitelik eleme işleminde kullanılmıştır.

Algoritma 1: Öznitelik eşleştirme algoritması

Veri Setindeki Her Görüntü Iç̧in:

Bütün Model Nesne Görüntüleri İçin:

Tanımlayıcı 1 = yerel öznitelikleri tanımla (Model Nesne Görüntüsü)

Tanımlayıcı 2 = yerel öznitelikleri tanımla (Foto-kapan Görüntüsü)

Eşleşmeler = kaba kuvvet eşleştirici(Tanımlayıcı 1, Tanımlayıcı 2)

\subsection{Aykırılık Tespiti ve Öznitelik Eleme}

Öznitelik eşleştirme işlemi görüntülerde benzer iki nesne arasında mutlak doğrulukta bir eşleşme ve tespit sağlayamamaktadır. Şekil 4'te gösterildiği üzere kırpılmış görüntü ile fotokapandan elde edilen görüntü eşleşmesinde yeşil renkli çizgiler eşleştirilmiş öznitelik noktalarını, kırmızı renkli pikseller ise eşleşmemiş öznitelik noktalarını temsil etmektedir. Görüntüdeki en benzer özniteliklerin eşleştirilmesi işlemi, bazen nesneye ait olmayan kısımların hatalı bir biçimde nesneye ait olarak etiketlenmesine, bu nedenle tespit işleminin hatalı yapılmasına neden olmaktadır.

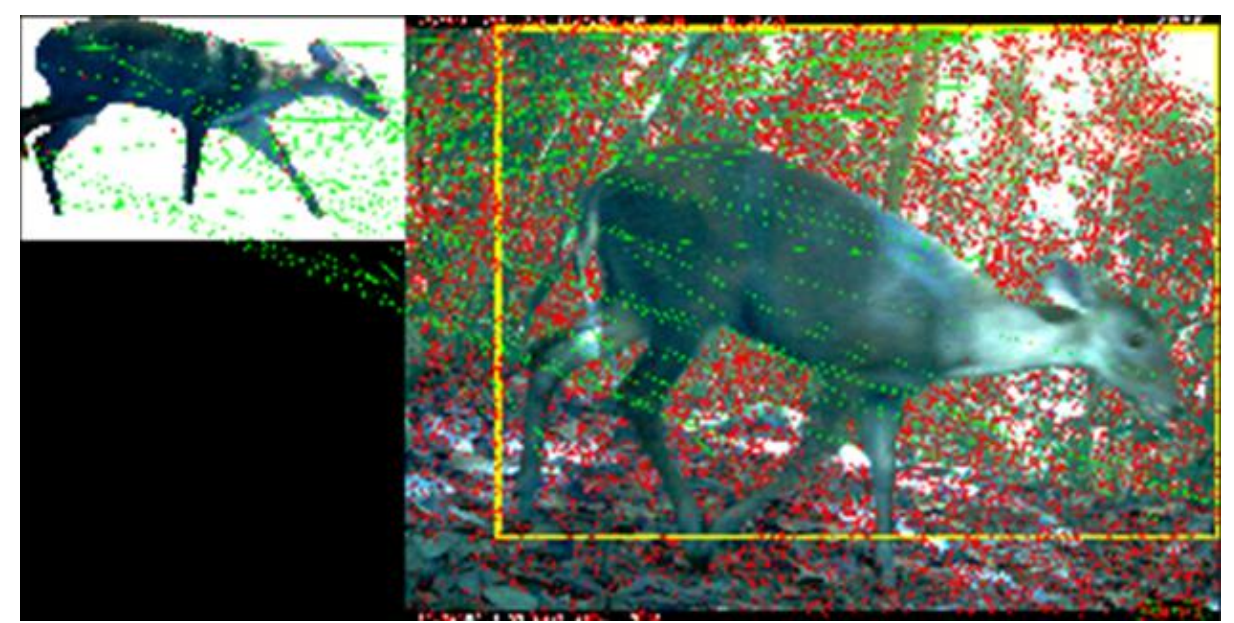

Şekil 4: Hatalı ve hatasız öznitelik eşleştirme sonucuna ait örnek görüntü 
Şekil 4'teki sarı sinırlayıcı kutunun nesnenin üzerindeki arka plan bölgesini de kapsadığı, yani bazı özniteliklerin hatalı olarak arka plandaki özniteliklerle eşleştiği anlaşılmaktadır. Bu hatalı özniteliklerin giderilmesi amacıyla çalışmamızda kaba kuvvet eşleştirici ile birlikte yüzdelik ve ortalama tabanlı aykırılık tespiti yöntemleri kullanılmıştır. Ayrıca k-en yakın komşu eşleştirici, farklı eşik değerleri ile birlikte kullanılarak öznitelik eleme işlemleri uygulanmıştır. Algoritma 2'de gösterildiği üzere, k-en yakın komşu eşleştiricisinde, tanımlayıcılardan eşleştirilmiş her $\mathrm{m}$ ve $\mathrm{n}$ eşleşme çiftinin uzaklıkları oranlanmış ve bu oran belirli bir değerin üzerinde ise eşleşme kabul edilmiştir.

Algoritma 2: k-en yakın komşu öznitelik seçme ve eleme algoritması

\begin{tabular}{l}
\hline Veri Setindeki Her Görüntü Iç̧in: \\
Bütün Model Nesne Görüntüleri Içcin: \\
Tanımlayıcı $1=$ yerel öznitelikleri tanımla (Model Nesne Görüntüsü) \\
Tanımlayııı $2=$ yerel öznitelikleri tanımla (Foto-kapan Görüntüsü) \\
Eşleşmeler = k-en yakın komş̧ eşleştirici(Tanımlayıcı 1, Tanımlayıcı 2, k=2) \\
Her m, neşleşmesi için: \\
Eğer m'nin mesafesi < [0.80, 0.85, 0.90, 0.95, 0.99] *n’nin mesafesi ise \\
Eşleşmeyi kabul et \\
Değil ise \\
Eşleşmeyi ele
\end{tabular}

Ortalama tabanlı aykırılık tespitinde kullanılan ortanca mutlak sapmanın (Median Absolute Deviation - MAD) nasıl hesaplandığ denklem (4)'te ifade edilmektedir. Hesaplanan ortanca mutlak sapma değerlerinden, parametrede girilen eşik değerden büyük olanlar aykırılık olarak tespit edilmiştir.

$$
M A D=\operatorname{median}(|x-\operatorname{median}(x)|)
$$

Yüzdelik tabanlı aykırılık tespitinde ise sıralı bir dizide girilen parametredeki konumlara karşıllık gelen elemanlarının değerlerini kullanarak maksimum ve minimum eşik değerleri belirlenmiştir. Dizide bu minimum ve maksimum değerlerin dışındaki elemanlar aykırılık olarak tespit edilmiştir.

\subsection{Sınırlayıcı Kutu Tespiti}

Sinırlayıcı kutu tespiti, aykırılık tespiti veya öznitelik eleme işlemi sonrasında kalan eşleştirilmiş özniteliklerin yerel $(\mathrm{x}, \mathrm{y})$ konum bilgilerinin kullanılması ile elde edilmiştir. Eşleşen özniteliklerin nesneyi temsil ettiği varsayıldığından, bu eşleşen özniteliklerin en küçük ve en büyük $(\mathrm{x}, \mathrm{y})$ noktalarının nesneyi kapsadığ1 kabul edilmiştir. Sınırlayıcı kutu tespitinde başarı ölçümü amaciyla denklem (5)'te gösterilen birleşimlerin kesişimi yöntemi (IoUIntersection Over Union) (Zitnick ve Dollar, 2014) 0.5 eşik değer parametresi ile kullanılmıştır.
İki sınırlayıcı kutu için konumlandırma ișlemi, bu iki kutunun kesiştiği bölgenin piksellerinin, iki kutunun birleşimi olan bölgenin piksellerine oranı 0.5 ve üzerinde ise başarılı kabul edilmiştir. Denklem (5)'te IoU sinırlayıcı kutunun başarı değerini, $B_{P}$ tahmin edilmiş sınırlayıcı kutuyu, $B_{G}$ ise gerçek sinırlayıcı kutuyu ifade etmektedir.

$I o U=\frac{B_{P} \cap B_{G}}{B_{P} \cup B_{G}}$

\section{Bulgular}

Çalışmamızda SIFT, SURF, BRIEF ve ORB yerel öznitelikleri, 2 farklı öznitelik eşleştirme yönteminde kullanılarak foto-kapan görüntülerinde nesne tespiti gerçekleştirilmiş olup, kaba kuvvet eşleştirici ile elde edilen sonuçlar Tablo 2 ve Tablo 5'te, k-en yakın komșu eşleştirici ile elde edilen sonuçlar ise Tablo 8 'de gösterilmiştir. Aykırılık tespiti ve öznitelik eleme işlemleri, hatalı eşleşmelerin giderilmesi ve sınırlayıcı kutu tespitinin daha doğru yapılmasını sağlamıştır. Hatalı öznitelik eşleşmelerinin elenmesinden sonra, tespit edilen sinırlayıc1 kutuların boyutları azalmış ve daha yüksek tespit başarısı elde edilmiştir. Eşleştirilen öznitelik sayısı ile sınırlayıcı kutu büyüklüğünün ilişkili olduğu ve tespit başarısını etkilediği gözlemlenmiştir. Tablo 1'de öznitelik tanımlayıcılarının boyutları gösterilmektedir. Tanımlayıcıların, özniteliklerin eşleştirilmesinde 
etkili olduğu ve bu nedenle bu boyutların tespit sonuçlarını arttırdığı anlaşılmaktadır.

Şekil 5'te k-en yakın komşu eşleştiricide, birinci görüntüdeki öznitelik tanımlayıcısı ile ikinci görüntüde bu öznitelik ile eşleşen en yakın 2 öznitelik tanımlayıcısının mesafelerinin birbirine olan oranlarının $0.99,0.95,0.90,0.85,0.80$ eşik değerlerine göre özniteliklerin elenmesi ve sinırlayıcı kutudaki değişiklikler gösterilmektedir. $\mathrm{Bu}$ oran azaldıkça sınırlayıcı kutular gerçek değerlerine yaklaşmakta ve tespit başarısı artmaktadır. k-en yakın komşu eşleştiricisinde, en yakın 2 komşunun elde edilmesi amacıyla $\mathrm{K}=2$ parametresi kullanılmıştır.

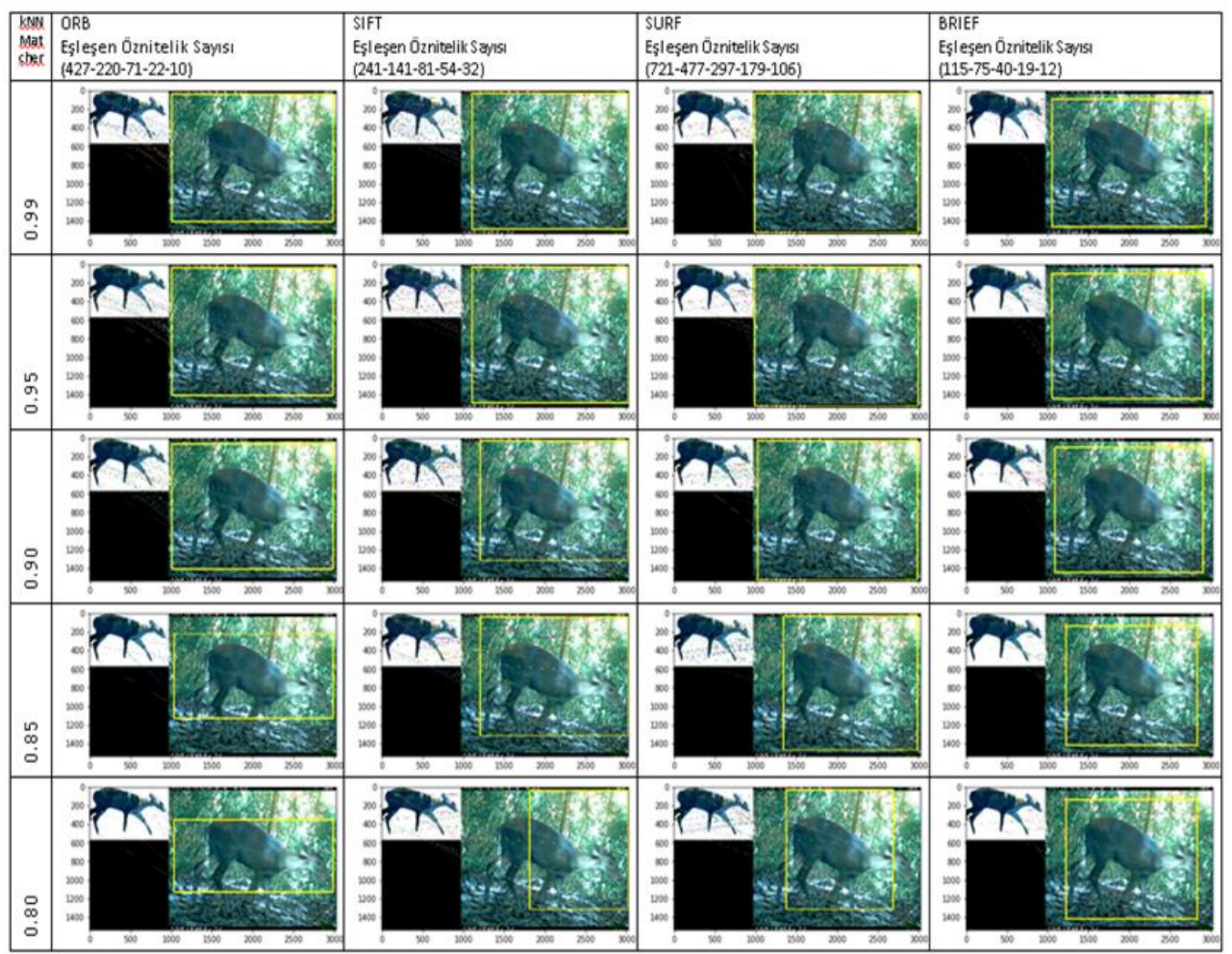

Şekil 5: k-en yakın komşu eşleştirme işleminde eşik değere göre öznitelik eleme sonrası sınırlayıcı kutu değişimi

Tablo 1: Özniteliklerin tanımlayıcı boyutları

\begin{tabular}{|c|c|c|c|c|}
\hline & SIFT & SURF & BRIEF & ORB \\
\hline $\begin{array}{c}\text { Tanımlayıcı } \\
\text { Uzunluğu }\end{array}$ & 128 & 64 & 256 & 256 \\
\hline $\begin{array}{c}\text { Tanımlayıcı } \\
\text { Boyutu } \\
\text { (Byte) }\end{array}$ & $\begin{array}{c}512 \\
\text { Byte }\end{array}$ & $\begin{array}{c}256 \\
\text { Byte }\end{array}$ & 32 Byte & $\begin{array}{c}32 \\
\text { Byte }\end{array}$ \\
\hline
\end{tabular}

Tablo 1: Yüzdelik tabanlı aykırılık tespiti sonrası nesne tespit başarı oranları

\begin{tabular}{|c|c|c|c|c|}
\hline $\begin{array}{c}\text { Yüzdelik } \\
\text { Parametre }\end{array}$ & ORB & BRIEF & SIFT & SURF \\
\hline 0.95 & 80.00 & 78.41 & 89.80 & 81.37 \\
\hline 0.90 & 81.59 & 79.47 & 90.99 & 83.36 \\
\hline 0.85 & 83.05 & 80.66 & 92.19 & 86.54 \\
\hline 0.80 & 84.64 & 82.91 & 93.38 & 87.86 \\
\hline 0.75 & 85.70 & 83.97 & 94.57 & 88.79 \\
\hline 0.70 & 87.02 & 85.83 & 95.76 & 89.72 \\
\hline
\end{tabular}

\begin{tabular}{|l|l|l|l|l|}
\hline 0.65 & 88.87 & 87.55 & 97.22 & 92.50 \\
\hline 0.60 & 90.60 & 88.34 & 98.68 & 94.22 \\
\hline 0.55 & 92.98 & 90.07 & 99.60 & 95.41 \\
\hline 0.50 & 95.23 & 91.52 & 99.66 & 96.60 \\
\hline
\end{tabular}

Yüzdelik tabanlı öznitelik eleme işleminde, Tablo 2, Tablo 3 ve Tablo 4'te 1. sütunda gösterilen öznitelik eleme parametre değeri azaldıkça, Tablo 4'teki ortalama eşleşen öznitelik sayılarının azaldığı, buna bağlı olarak Tablo 3'teki ortalama sınırlayıcı kutuların gerçek değerlere yaklaştığı ve bunun sonucunda Tablo 2'de nesne tespit başarısında artış elde edildiği anlaşılmaktadır. Tablo 2, Tablo 3 ve Tablo 4'te görüldügü üzere, yüzdelik tabanlı aykırılık tespiti işleminde, eşleşmelerin ortalama olarak yaklaşık yarısının elendiği ve bu durumun nesne tespit başarısını \%10-\%15 arası arttırdığı anlaşılmaktadır. 
Tablo 3: Yüzdelik tabanlı aykırılık tespiti sonrası ortalama sınırlayıcı kutu boyutları (piksel)

\begin{tabular}{|c|c|c|c|c|}
\hline $\begin{array}{c}\text { Yüzdelik } \\
\text { Parametre }\end{array}$ & ORB & BRIEF & SIFT & SURF \\
\hline 0.95 & 473 & 418 & 498 & 544 \\
\hline 0.90 & 423 & 383 & 455 & 486 \\
\hline 0.85 & 382 & 354 & 416 & 443 \\
\hline 0.80 & 350 & 326 & 381 & 404 \\
\hline 0.75 & 322 & 303 & 347 & 372 \\
\hline 0.70 & 294 & 280 & 313 & 344 \\
\hline 0.65 & 270 & 259 & 280 & 319 \\
\hline 0.60 & 249 & 235 & 280 & 295 \\
\hline 0.55 & 228 & 213 & 249 & 269 \\
\hline 0.50 & 209 & 193 & 218 & 245 \\
\hline
\end{tabular}

Tablo 2: Yüzdelik tabanlı aykırılık tespiti sonras1 ortalama eșleșen öznitelik sayıları

\begin{tabular}{|c|c|c|c|c|}
\hline $\begin{array}{c}\text { Yüzdelik } \\
\text { Parametre }\end{array}$ & ORB & BRIEF & SIFT & SURF \\
\hline 0.95 & 1182 & 197 & 471 & 1490 \\
\hline 0.90 & 1121 & 187 & 447 & 1422 \\
\hline 0.85 & 1062 & 177 & 422 & 1354 \\
\hline 0.80 & 1000 & 167 & 397 & 1286 \\
\hline 0.75 & 939 & 158 & 373 & 1220 \\
\hline 0.70 & 877 & 148 & 348 & 1151 \\
\hline 0.65 & 816 & 137 & 323 & 1084 \\
\hline 0.60 & 754 & 128 & 323 & 1008 \\
\hline 0.55 & 693 & 117 & 298 & 919 \\
\hline 0.50 & 633 & 107 & 273 & 839 \\
\hline
\end{tabular}

Bütün sonuçlarda en yüksek nesne tespit başarısı bütün öznitelik eleme yöntemlerinde SIFT özniteliği ile elde edilmiş olup, ona en yakın sonuçlar ise SURF özniteliğinde elde edilmiştir. Tablo 1'de görüldüğü üzere, en yüksek boyutlu öznitelik tanımlayıcısı olan SIFT ile en yüksek tespit başarısı elde edilmiştir. Diğer dönüşüm yöntemleri, öznitelik dönüştürme veya eşleştirme işlemini hızlandırmayı veya öznitelikleri daha az boyutta temsil etmeyi amaçladığından daha düşük tespit başarısı elde edilmiştir.

Tablo 7'den anlaşıldığı üzere ortalama tabanlı aykırılık tespitinde, öznitelik eşleşmelerinin \%35\%40'1 elenmiştir. Yüzdelik tabanlı eleme yöntemine göre daha az öznitelik elenmiș ve buna bağlı olarak Tablo 5'teki gösterilen nesne tespit başarısında Tablo 2' deki yüzdelik tabanlı yönteme göre daha düşük tespit başarısı elde edilmiştir.
Tablo 6'da görüldüğü üzere ortalama tabanlı aykırılık tespitinde elde edilen sınırlayıcı kutuların yüzdelik tabanlı aykırılık tespitinde elde edilenlere göre daha küçük boyutlu olduğu anlaşılmaktadır.

Tablo 5: Ortalama tabanlı aykırılık tespiti sonras1 nesne tespit başarı oranları

\begin{tabular}{|c|c|c|c|c|}
\hline $\begin{array}{c}\text { Ortalama } \\
\text { Parametresi }\end{array}$ & ORB & BRIEF & SIFT & SURF \\
\hline 2.5 & 78.15 & 76.69 & 90.07 & 82.65 \\
\hline 2.0 & 81.85 & 81.99 & 94.30 & 87.15 \\
\hline 1.5 & 84.90 & 85.43 & 96.29 & 91.26 \\
\hline 1.0 & 87.95 & 87.81 & 97.88 & 93.11 \\
\hline
\end{tabular}

Tablo 3: Ortalama tabanlı aykırılık tespiti sonrası sinırlayıcı kutu boyutları (piksel)

\begin{tabular}{|c|c|c|c|c|}
\hline $\begin{array}{c}\text { Ortalama } \\
\text { Parametresi }\end{array}$ & ORB & BRIEF & SIFT & SURF \\
\hline 2.5 & 389 & 351 & 470 & 423 \\
\hline 2.0 & 340 & 314 & 428 & 376 \\
\hline 1.5 & 277 & 260 & 351 & 314 \\
\hline 1.0 & 201 & 187 & 229 & 228 \\
\hline
\end{tabular}

Tablo 4: Ortalama tabanlı aykırılık tespiti sonrası eşleşen öznitelik sayıları

\begin{tabular}{|c|c|c|c|c|}
\hline $\begin{array}{c}\text { Ortalama } \\
\text { Parametresi }\end{array}$ & ORB & BRIEF & SIFT & SURF \\
\hline 2.5 & 1060 & 177 & 462 & 1300 \\
\hline 2.0 & 985 & 167 & 440 & 1216 \\
\hline 1.5 & 872 & 149 & 393 & 1074 \\
\hline 1.0 & 682 & 116 & 299 & 851 \\
\hline
\end{tabular}

k-en yakın komşu eşleștirme işleminde elde edilen sonuçlar incelendiğinde, Tablo 9'daki sınırlayıcı kutu boyutlarının, olmasi gereken nesne boyutlarından daha küçük olduğu ve bu nedenle düşük tespit başarısı elde edildiği anlaşılmaktadır.

Tablo 5: k-en yakın komşu tabanlı öznitelik eleme sonrası nesne tespit başarı oranları (\%)

\begin{tabular}{|c|c|c|c|c|}
\hline $\begin{array}{c}\text { kNN } \\
\text { Parametresi }\end{array}$ & ORB & BRIEF & SIFT & SURF \\
\hline 0.95 & 64.50 & 55.76 & 73.91 & 64.64 \\
\hline 0.90 & 73.64 & 69.80 & 80.79 & 71.13 \\
\hline 0.85 & 75.36 & 70.86 & 80.66 & 75.23 \\
\hline 0.80 & 75.63 & 72.05 & 82.38 & 77.88 \\
\hline
\end{tabular}


Tablo 6: k -en yakın komşu tabanlı öznitelik eleme sonrası sinırlayıc1 kutu boyutları (piksel)

\begin{tabular}{|c|c|c|c|c|}
\hline $\begin{array}{c}\text { kNN } \\
\text { Parametresi }\end{array}$ & ORB & BRIEF & SIFT & SURF \\
\hline 0.95 & 207 & 191 & 255 & 224 \\
\hline 0.90 & 203 & 185 & 250 & 220 \\
\hline 0.85 & 196 & 177 & 237 & 204 \\
\hline 0.80 & 166 & 139 & 184 & 169 \\
\hline
\end{tabular}

Tablo 10'da gösterildiği üzere, k-en yakın komşu öznitelik eleme işleminde 1. sütundaki öznitelik yakınlık mesafe parametresindeki her 0.05 'lik azalmaya karşılık öznitelikler oldukça yüksek oranda elenmişlerdir. $\mathrm{Bu}$ işlemde özniteliklerin $\% 40$ ile \%50'sinin elenmesine karşılık, Tablo 9'daki sinırlayıc1 kutularda $\% 7$ ile $\% 20$ oranlarında küçülme gerçekleşmiş, bunun sonucunda ise Tablo 8'deki nesne tespit başarısı $\% 5$ ile $\% 17$ arasında artmıştır.

Tablo 7: k-en yakın komşu tabanlı öznitelik eleme sonrası eşleșen öznitelik sayısı

\begin{tabular}{|c|c|c|c|c|}
\hline $\begin{array}{c}\text { kNN } \\
\text { Parametresi }\end{array}$ & ORB & BRIEF & SIFT & SURF \\
\hline 0.95 & 1237 & 206 & 494 & 1559 \\
\hline 0.90 & 608 & 125 & 274 & 977 \\
\hline 0.85 & 238 & 66 & 133 & 548 \\
\hline 0.80 & 32 & 20 & 34 & 173 \\
\hline
\end{tabular}

Eşleşen öznitelikler sayıları ile nesne tespit başarı oranı karşılaştırıldığında, en iyi sonuç Tablo 11'de görüldüğü üzere BRIEF öznitelik tanımlayıcısında elde edilmiştir. Ayrıca k-en yakın komşu eşleştirme ve eleme işleminin, kaba kuvvet eşleştiricisi yüzdelik ve ortalama aykırılık tespitine göre, eşleşen öznitelik sayıları ile nesne tespit başarılarına oranına göre daha iyi olduğu Tablo 11'den anlaşılabilmektedir.

Tablo 8: Nesne tespit başarı oranları ile eşleşen öznitelik sayıları ilişkisi (tespit başarı oranı / eşleşen öznitelik sayıs1 * 100)

\begin{tabular}{|c|c|c|c|c|}
\hline $\begin{array}{c}\text { Aykırilk } \\
\text { Tespiti ve } \\
\begin{array}{c}\text { Öznitelik } \\
\text { Eleme }\end{array}\end{array}$ & ORB & BRIEF & SIFT & SURF \\
\hline Yüzdelik & 7.3 & 42.6 & 20.1 & 6.2 \\
\hline Ortalama & 6.1 & 34.4 & 16.3 & 4.8 \\
\hline kNN & 8.3 & 49.6 & 21.2 & 7.2 \\
\hline
\end{tabular}

\section{Sonuç ve Tartışma}

Bu çalışmada SIFT, SURF, BRIEF ve ORB yerel öznitelikleri, kaba kuvvet ve k-en yakın komşu öznitelik eşleştirme yöntemleri kullanılarak fotokapan görüntülerinde nesne tespit işlemi gerçekleştirilmiştir. $\mathrm{Bu}$ yerel öznitelik tanımlayıcılarından elde edilen tespit sonuçları ile birlikte, eşleşen öznitelik sayıları ve elde edilen sınırlayıcı kutuların boyutları değerlendirilmiştir. Öznitelik eşleşme işlemindeki hataların, nesne tespitindeki sınırlayıcı kutuların büyük olmasına neden olduğu ve nesne tespit başarısını düşürdüğü anlaşılmaktadır. Ayrıca eşleşen öznitelik sayıları ile nesne tespit başarılarının ilişkisi çıkarılarak, öznitelik tanımlayıcılarının eşleşen özniteliklerin nesne tespit başarısına etkisi incelenmiştir.

Yerel öznitelik tanımlayıcılarının nesne tespit etmede, çok sayıda görüntü barındıran veri setleri ile eğitime ihtiyaç duymadan, birkaç model görüntü kullanılarak başarılı sonuçlar elde edilebileceği gözlemlenmiştir.

Sonraki çalışmalarda yerel öznitelik tanımlayıcılarının işlem ve bellek gereksinimleri incelenerek dağıtık ve gömülü sistemler üzerinde uygulanabilirliğinin araştırılması planlanmaktadır.

\section{Teşekkür}

$\mathrm{Bu}$ çalı̧̧ma Atatürk Üniversitesi Bilimsel Araştırma Projelerini destekleme programı kapsamında FYL-2018-6623 proje kodu ile desteklenmiştir.

\section{Kaynaklar}

Andavarapu, N., \& Vatsavayi, V. K. (2017). WildAnimal Recognition in Agriculture Farms Using W-COHOG for Agro-Security. International Journal of Computational Intelligence Research, 13(9), 2247-2257.

Bay, H., Tuytelaars, T., \& Van Gool, L. (2006, May). Surf: Speeded up robust features. In European conference on computer vision (pp. 404-417). Springer, Berlin, Heidelberg.

Calonder, M., Lepetit, V., Strecha, C., \& Fua, P. (2010, September). Brief: Binary robust independent elementary features. In European conference on computer vision (pp. 778-792). Springer, Berlin, Heidelberg.

Chen, Q., Song, Z., Dong, J., Huang, Z., Hua, Y., \& Yan, S. (2015). Contextualizing object detection and classification. IEEE transactions on pattern analysis and machine intelligence, 37(1), 13-27. 
Karakuş, P., \& Karabörk, H. "Surf Algoritması Kullanılarak Uzaktan Algılama Görüntülerinin Geometrik Kaydı". 5. Uzaktan Algılama-Cbs Sempozyumu (Uzal-Cbs 2014), 14-17 Ekim 2014, İstanbul.

Karami, E., Prasad, S., \& Shehata, M. (2017). Image matching using SIFT, SURF, BRIEF and ORB: performance comparison for distorted images. arXiv preprint arXiv: 1710.02726.

Karami, E., Shehata, M., \& Smith, A. (2017). Image Identification Using SIFT Algorithm: Performance Analysis against Different Image Deformations. arXiv preprint arXiv: 1710.02728 .

Kays, R., Tilak, S., Kranstauber, B., Jansen, P. A., Carbone, C., Rowcliffe, M. J., ... \& He, Z. (2010). Monitoring wild animal communities with arrays of motion sensitive camera traps. arXiv preprint arXiv:1009.5718.

Khorrami, P., Wang, J., \& Huang, T. (2012, November). Multiple animal species detection using robust principal component analysis and large displacement optical flow. In Proceedings of the 21st International Conference on Pattern Recognition (ICPR), Workshop on Visual Observation and Analysis of Animal and Insect Behavior (pp. 11-15).

Lisin, D. A., Mattar, M. A., Blaschko, M. B., LearnedMiller, E. G., \& Benfield, M. C. (2005, June). Combining local and global image features for object class recognition. In Computer vision and pattern recognition-workshops, 2005. CVPR workshops. IEEE Computer society conference on (pp. 47-47). IEEE.

Lowe, D. G. (1999). Object recognition from local scale-invariant features. In Computer vision, 1999. The proceedings of the seventh IEEE international conference on (Vol. 2, pp. 11501157). IEEE.

Lowe, D. G. (2001). Local feature view clustering for 3D object recognition. In Computer Vision and Pattern Recognition, 2001. CVPR 2001. Proceedings of the 2001 IEEE Computer Society Conference on (Vol. 1, pp. I-I). IEEE.

Meek, P. D., Ballard, G., Claridge, A., Kays, R., Moseby, K., O’brien, T., \& Townsend, S. (2014). Recommended guiding principles for reporting on camera trapping research. Biodiversity and conservation, 23(9), 23212343.

Murphy, K., Torralba, A., Eaton, D., \& Freeman, W. (2006). Object detection and localization using local and global features. In Toward CategoryLevel Object Recognition (pp. 382-400). Springer, Berlin, Heidelberg.
Nguyen, H., Maclagan, S. J., Nguyen, T. D., Nguyen, T., Flemons, P., Andrews, K., ... \& Phung, D. (2017, October). Animal recognition and identification with deep convolutional neural networks for automated wildlife monitoring. In Data Science and Advanced Analytics (DSAA), 2017 IEEE International Conference on (pp. 4049). IEEE.

Norouzzadeh, M. S., Nguyen, A., Kosmala, M., Swanson, A., Palmer, M. S., Packer, C., \& Clune, J. (2018). Automatically identifying, counting, and describing wild animals in camera-trap images with deep learning. Proceedings of the National Academy of Sciences, 201719367.

Rublee, E., Rabaud, V., Konolige, K., \& Bradski, G. (2011, November). ORB: An efficient alternative to SIFT or SURF. In Computer Vision (ICCV), 2011 IEEE international conference on(pp. 2564-2571). IEEE.

Se, S., Lowe, D., \& Little, J. (2002). Mobile robot localization and mapping with uncertainty using scale-invariant visual landmarks. The international Journal of robotics Research, 21(8), 735-758.

Snavely, N., Seitz, S. M., \& Szeliski, R. (2008, June). Skeletal graphs for efficient structure from motion. In CVPR (Vol. 1, p. 2).

Tuytelaars, T., \& Mikolajczyk, K. (2008). Local invariant feature detectors: a survey.

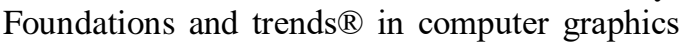
and vision, 3(3), 177-280.

Yu, X., Wang, J., Kays, R., Jansen, P. A., Wang, T., \& Huang, T. (2013). Automated identification of animal species in camera trap images. EURASIP Journal on Image and Video Processing, 2013(1), 52.

Zhang, J., Marszałek, M., Lazebnik, S., \& Schmid, C. (2007). Local features and kernels for classification of texture and object categories: A comprehensive study. International journal of computer vision, 73(2), 213-238.

Zhang, Z., He, Z., Cao, G., \& Cao, W. (2016). Animal detection from highly cluttered natural scenes using spatiotemporal object region proposals and patch verification. IEEE Transactions on Multimedia, 18(10), 2079-2092.

Zitnick, C. L., \& Dollár, P. (2014, September). Edge boxes: Locating object proposals from edges. In European conference on computer vision (pp. 391-405). Springer, Cham. 